\title{
Avaliação de Cinco Híbridos de Milho (Zea mays, L.) em Diferentes Estádios de Maturação. 2. Concentrações dos Componentes Estruturais e Correlações ${ }^{1,2}$
}

\section{Juliano Ricardo Fontanini Beleze ${ }^{3}$, Lúcia Maria Zeoula 4 , Ulysses Cecato ${ }^{4}$, Paulo Henrique Moura Dian ${ }^{5}$, Elias Nunes Martins ${ }^{4}$, Alencariano José da Silva Falcão ${ }^{6}$}

\begin{abstract}
RESUMO - Este trabalho foi conduzido para avaliar a concentração de componentes estruturais de cinco híbridos de milho Pioneer: o superprecoce P32R21, os precoces P30R07, P3041, P30F33 e o semiprecoce P30F80, em cinco estádios de maturação. O delineamento utilizado foi de blocos ao acaso, com cinco tratamentos e quatro repetições. A colheita das plantas dos híbridos de milho foi realizada em cinco estádios de maturação propostos: 30, 34, 38, 42 e 46\% de matéria seca (MS). Para cada estádio de maturação, procedeu-se à separação de colmo + bainha, lâmina foliar, grão, sabugo e palha. Depois das pesagens e com posterior determinação dos teores de MS, foram obtidas as concentrações $(\%)$ de grão, de sabugo + palha, de espiga, de colmo + bainha e de lâmina foliar em relação à planta inteira dos cinco híbridos, nos cinco estádios de maturação. Para todos os parâmetros avaliados, os híbridos diferiram entre si e apresentaram significância de dias pósplantio (DPP). Ficou caracterizado que, com o avanço do estádio de maturidade da planta, ocorreram aumento nas concentrações (\%) de espiga e grãos e diminuição nas concentrações da lâmina foliar e colmo + bainha em relação à MS da planta inteira.
\end{abstract}

Palavras-chave: espiga, estádios de maturação, fração vegetativa, grãos, milho

\section{Evaluation of Five Corn Hybrids (Zea mays, L.) at Different Maturity Stages. 2. Structural Component Concentrations and Correlations}

\begin{abstract}
This study was conducted to evaluate the structural component concentrations of five hybrids of Pioneer corn: P32R21, P30R07, P3041, P30F33 and P30F80, at different maturity stages. The treatments were used in plots of $7 \mathrm{x} 8 \mathrm{~m}$ in a randomized block design, with four replicates. The samples collected, of corn hybrid, were adopted trying to estimate phases of maturity of the plant $(30,34,38,42$ and $46 \%$ of dry matter [DM]). For each maturation stage, was done separation of stem + sheath, leaf lamina, grain, cob and straw. After the weight and with posterior determination of DM crude, it was possible to obtain the concentrations and relations $(\%)$ of grain, cob + straw, ear of the corn, stem + sheath and leaf lamina in the whole plant of five hybrids at different maturation stage. For all the evaluated parameters, the hybrids were different and showed significant effect at days after seeding (DAS). It was observed that as the plant maturity stage (DAS) advanced, an increase of ear and grain concentration and a decrease of the structure component (leaf lamina, stem + sheath) in a DM the whole plant were observed.
\end{abstract}

Key Words: corn, ear, grain, stages of maturity, vegetative fraction

\section{Introdução}

Nos sistemas de produção animal em confinamento, o principal volumoso utilizadoé a silagem de milho. Nos demais sistemas, principalmente no período de escassez de forragens, a suplementação volumosa também é feita à base de silagem, principalmente de milho, sorgo ou gramíneas. Nesse último tipo de sistema, dependendo do nível de escassez das pastagens, a silagem poderá ser, nesses períodos, o principal volumoso disponível aos animais.

É sabido que alta produtividade está relacionada com boas práticas de manejos culturais ou, em outras palavras, com emprego de tecnologia. Qualidade da semente, preparo químico e físico do solo, adubações, controle de ervas daninhas, pragas e doenças, irrigação, época de plantio, espaçamentos, etc, são fatores que afetam a quantidade de milho produzido por unidade de área. Porém, informações sobre seus efeitos em relação à qualidade do material a ser ensilado, ainda são poucas, nas condições do Brasil.

Segundo Ferreira (1990b), a deficiência de pesquisa e difusão de tecnologia, com enfoque de sistema, abrangendo todas as etapas de produção da

\footnotetext{
1 Projeto financiado pela PIONEER SEMENTES, com parceria da FUNDAÇÃO ABC.

2 Parte da Dissertação de Mestrado apresentada pelo primeiro autor.

3 Médico - Veterinário, mestre em Produção Animal - PPZ/UEM. E.mail: jbeleze@hotmail.com

4 Professores do PPZ/ DZO/UEM. Av. Colombo, 5790 - 87020-900, Maringá - PR; Bolsista do CNPq. E.mail: Imzeoula@uem.br

5 Estudante de graduação em Zootecnia - DZO/ UEM - Bolsista de Iniciação Científica/ CNPq.

6 Estudante de doutorado em Melhoramento Genético - PPZ/UEM.
} 
silagem de milho, da cultura até sua utilização por animais em produção, constitui a principal razão da baixa participação do milho como forragem na alimentação de bovinos no Brasil.

Nevens \& Dungam (1949) trabalharam por sete anos consecutivos com silagens de milho produzidas por vários híbridos comerciais e com plantas originadas de sementes provenientes de polinização aberta. O grupo de híbridos comerciais apresentou vantagens significativas sobre as variedades originadas de polinização aberta, em relação à produção de matéria seca da planta toda e de grãos. Os híbridos comerciais foram mais resistentes ao acamamento, do que os híbridos provenientes de polinização aberta. Os valores médios, dos sete anos, da percentagem matéria seca (MS) da planta, da haste, da folha e da espiga foram, respectivamente, de 31,6;21,4; 29,6 e 45,0\% em relação à da planta toda. Os autores concluíram que o principal responsável para elevar a matéria seca da planta e manter a qualidade da silagem foi à espiga. Huber et al. (1965) também demonstraram que a participação da espiga na produção de MS total aumentou com o avanço da maturidade. Naquele trabalho, a percentagem da produção de MS total representada pelas espigas, folhas e haste foi, respectivamente, de $34,0 \%, 35,0 \%$ e $31,0 \%$ para o estágio de grão leitoso; $47,0 \%, 28,0 \%$ e $25,0 \%$ para o estádio de grão pastoso e de $51,5 \%, 25,0 \%$ e $24,0 \%$ para o estádio de grão farináceo, respectivamente. Não houve efeito significativo dos estádios de maturação sobre o valor nutritivo da planta, expresso pela porcentagem de nutrientes digestíveis totais (NDT). A composição do leite produzido, o ganho de peso vivo e a eficiência na produção de leite não foram afetados pelo estádio de desenvolvimento do milho no momento da ensilagem.

Pesquisas feitas nos Estados Unidos mostraram que nem sempre a maior proporção de grãos na forragem confere uma melhor qualidade à silagem. Portanto, a qualidade do grão e da fração vegetativa da planta (caule, folha e palha), combinada com o percentual de cada uma dessas partes na planta, determina o valor nutritivo do material ensilado (Johnson et al., 1985).

Segundo Émile \& Barrière (1992), avaliações dos diferentes híbridos possibilitam a melhora no valor nutritivo de silagens por intermédio da seleção de genótipos com melhor equilíbrio entre colmos, folhas e espigas. Deste modo, a recomendação das variedades que apresentam maiores índices de produtividade e qualidade da forragem irá refletir em eficiência da produção animal. Demarquilly (1994) ressaltou que a fração colmo e folha é de grande importância e, quando a quantidade de grãos entre duas variedades é próxima, é preferível optar pela variedade que apresenta mais folhas. Assim, resultará em aumento na quantidade de matéria seca com maior valor energético.

Estudos realizados em 1998, no Institut National de la Recherche Agronomique - França (INRA) revelaram que o teor de grãos não foi suficiente para predizer o valor alimentar da silagem de milho e que a digestibilidade da parede celular também não, mas o resultado dos dois fatores é que determina o seu valor energético.

Híbridos de milho com maiores proporções de fração vegetativa, em relação ao grão, podem apresentar maior valor nutritivo e são de interesse de produtores de leite nos Estados Unidos da América, no uso de ração completa, pois, diminuíram a ocorrência de doenças provocadas pelo uso de grande proporção de concentrado (grão) na alimentação (Mayombo et al., 1997).

Lavezzo et al. (1997), avaliando quatro estádio de maturidade de híbridos de milho: grãos no ponto leitoso, no ponto pamonha, no ponto farináceo e grãos no ponto semi-duro, verificaram tendências nas reduções de folhas de 34,1 para $23,6 \%$ e de hastes de 33,3 para $27,1 \%$ e aumento percentual de espigas de 35,5 para $49,1 \%$, à medida que as plantas foram colhidas com os grãos no estádio leitoso para o semi-duro.

Este trabalho foi conduzido com o objetivo de avaliar cinco híbridos de milho (Zea mays, L), em cinco estádios de maturidade, quanto à concentração de componentes estruturais para produção de silagem.

\section{Material e Métodos}

O plantio dos híbridos de milho Pioneer foi realizado na fazenda experimental "Capão Alto", pertencente à Fundação ABC, formada pelas Cooperativas Arapoti Ltda, Agropecuária Batavo Ltda e Sociedade Cooperativa Castrolanda, localizada no município de Castro, região sul do Estado do Paraná.

O plantio dos híbridos foi realizado em outubro de 1999 e as colheitas das amostras foram iniciadas em fevereiro de 2000, prolongando-se até o final de março de 2000.

$\mathrm{O}$ estabelecimento da cultura foi realizado em uma área plana de solo Latossólico vermelho amarelo. A análise do solo revelou as seguintes características: 
$\mathrm{pH} 5,1 ; \mathrm{P}-96 \mathrm{mg} / \mathrm{dm}^{3} ; \mathrm{Al}^{+++}-1 \mathrm{mg} / \mathrm{dm}^{3}$; $\mathrm{K}-3,4 \mathrm{cmol} / \mathrm{dm}^{3} ; \mathrm{Ca}^{++}-33 \mathrm{cmol} / \mathrm{dm}^{3} ; \mathrm{H}^{+}+\mathrm{Al}^{+++}$ - $58 \mathrm{mg} / \mathrm{dm}^{3} ; \mathrm{Mg}-17 \mathrm{cmol} / \mathrm{dm}^{3}$ e matéria orgânica$46 \mathrm{mg} / \mathrm{dm}^{3}$.

Para o estabelecimento da cultura de milho, a área foi arada e posteriormente gradeada para destorroamento, nivelamento e abertura dos sulcos. Por ocasião da semeadura, em sulcos espaçados de $80 \mathrm{~cm}$, foi aplicado adubo correspondente a $150 \mathrm{~kg} / \mathrm{ha}$, da fórmula 15-30-0 (N-P-K) e adubação orgânica com esterco bovino 30.000 Litros/ha. Realizou-se também uma adubação em cobertura com $250 \mathrm{~kg} / \mathrm{ha}$, da fórmula 25-0-5 (N-P-K).

Foram avaliados cinco cultivares de milho híbrido Pioneer: superprecoce 32R21 (P32R21), precoce 30R07 (P30R07), precoce 3041 (P3041), precoce 30F33 (P30F33) e semiprecoce 30F80 (P30F80). O delineamento experimental utilizado foi de blocos ao acaso, com cinco tratamentos e quatro repetições.

A colheita das amostras dos híbridos de milho foi adotada tentando obedecer cinco estádios de maturação da planta: 30, 34, 38, 42 e 46\% de MS, totalizando 100 amostras da planta inteira (5 estádios de maturação, 5 híbridos, 4 repetições). Com a finalidade de se alcançar os cinco estádios de maturação, observou-se o dia pós plantio(DPP), que correspondeu ao dia em que as amostras de cada híbrido foram colhidas no campo, obedecendo uma ordem cronológica (ciclo de pendoamento de cada híbrido), monitoramento da consistência do grão nas plantas da bordadura e a utilização de dados referentes à MS dos mesmos híbridos, plantados no mesmo período, mas em ano anterior.

A parcela experimental foi constituída de 11 linhas de sete metros de comprimento e com espaçamento de $80 \mathrm{~cm}$, totalizando oito metros de largura, portanto, a área de cada parcela utilizada correspondeu a $61,6 \mathrm{~m}^{2}$. Foi considerada uma área útil de $36 \mathrm{~m}^{2}$ em cada parcela, sendo que duas linhas laterais e hum metro das duas extremidades foram consideradas como bordaduras, portanto, as amostras foram obtidas das nove linhas restantes, fazendo-se uso de toda parcela experimental.

Em todos os estádios de maturação, foram colhidas três plantas/linha/parcela, totalizando 27 plantas amostradas/parcela (9 linhas na parcela). A colheita foi precedida de sorteio, desprezando-se plantas fora do padrão (outlier = 2 plantas/cova), e preocupou-se em não retirar plantas seguidamente, para evitar possíveis espaços (clarões) entre plantas, que pudes- sem também conduzir a um efeito competitivo entre elas. Das 27 plantas colhidas, uma foi utilizada para amostra de planta inteira, e as demais, para amostras de colmo + bainha, lâmina foliar e grão, em cada estádio de maturação. Depois de corte realizado a $45 \mathrm{~cm}$ do solo, com foice, todas as plantas da mesma parcela eram agrupadas, identificadas e transportadas para um local apropriado.

Para cada estádio de maturação, procedeu-se à pesagem, em balança com capacidade de $15 \mathrm{~kg}$, da massa verde de cada planta colhida individualmente e, posteriormente, foi feita a separação de colmo + bainha, lâmina foliar, grão, sabugo e palha para pesagem destes.

Depois das pesagens e com posterior determinação do teor de MS, pode-se obter as relações (\%) de grão, de espiga, de sabugo + palha, de colmo + bainha e de lâmina foliar na planta inteira dos híbridos, nos cinco estádios de maturação.

Procedeu-se à análise exploratórias dos dados e mostraram que as variáveis: teores de matéria seca e percentagem de colmo, não apresentaram distribuição normal $(\mathrm{P}<0,01)$. Então, admitiu-se uma distribuição gama para o erro em um Modelo Linear Generalizado (GLIM 4.0), como descrito por Nelder e Wedderburn (1972). Aquelas variáveis que se distribuíram normalmente em torno da média, as análises estatísticas, foram realizadas pelo aplicativo SAS 8.01.

\section{Resultados e Discussão}

Quanto à percentagem de espiga em relação à matéria seca da planta inteira, houve diferença $(\mathrm{P}<0,05)$ entre híbridos (Tabela 1) e observou-se efeito linear para DPP $(\mathrm{P}<0,05)$. Variação na proporção de espiga de 63,62 a 70,25\% foram observadas entre os híbridos, o menor valor foi para o híbrido semiprecoce P30F80 e, o maior valor, para o híbrido superprecoce P32R21. Estas proporções de espiga são superiores às encontradas na literatura (Nevens \& Dungam, 1942; Huber et al., 1965; Souza, 1989; Hunt et al., 1993; Henrique et al., 1994; Almeida Filho, 1996; Lavezzo et al., 1997; Almeida Filho et al., 1999; Silva et al., 1999; Flaresso et al., 2000).

Para as percentagens de grãos na matéria seca da planta inteira, nos diferentes estádios de maturação, houve diferença entre os híbridos $(\mathrm{P}<0,01)$ e de DPP $(\mathrm{P}<0,01)$. A maior participação de grãos na planta inteira foi observada para o híbrido superprecoce P32R21, média de 54,20\%, e a menor percentagem 
de grãos foi verificada para o híbrido semiprecoce P30F80, média de 44,03\%. Entre os híbridos precoces, o P30R07 (51,28\%) diferiu do P3041 e do P30F33, que não diferiram entre si, com médias de 47,75 e 47,46\%, respectivamente (Tabela 1).

As proporções médias de grãos, nos diferentes estádios de maturação, são semelhantes aos valores relatados por Johnson et al. (1985) para o Pioneer 3055, Pioneer 3147 e Americus Seed ASC 89 com 48, 53 , e $51 \%$, respectivamente, e superiores aos valores de 41 e $44 \%$ para os híbridos Pioneer 3377 e Pioneer 3389, relatados por Hunt et al. (1993) e aos valores de 27 a $42 \%$ para os híbridos Cargill-435 e Agroceres 1051, relatados por Almeida Filho (1996).

As proporções de sabugo + palha em relação à planta inteira variaram em média de 16,05 a 20,97\%, diferindo $(\mathrm{P}<0,01)$ entre os híbridos, sendo o menor valor para o híbrido superprecoce P32R21 e o maior valor para o híbrido semiprecoce P30F80 (Tabela 1).

As percentagens médias de lâmina foliar em relação à matéria seca da planta inteira variaram de 10,54 a $14,24 \%$, sendo o menor valor $(\mathrm{P}<0,05)$, para o híbrido superprecoce P32R21 e o maior para o híbrido semiprecoce P30F80 (Tabela 1). Entre os híbridos precoces P30R07, P3041 e P30F33, não houve diferença para a percentagem de lâmina foliar, em média de $12,88 \%$. Estes resultados são inferiores aos 14,64 a 16,10\% de folha em relação à planta inteira, encontrados por Henrique et al. (1994), nos híbridos Colorado-29 e Cargil-135, e aqueles encontrados por Flaresso et al. (2000), de 15,70 a $18,90 \%$. Vale ressaltar que os dados obtidos no presente trabalho são referentes apenas à lâmina foliar e não folha (lâmina + bainha), o que proporcionou menor concentração em relação à planta inteira.

Em relação aos teores de MS dos híbridos de milho em função de DPP, observou-se comportamento cúbico $(\mathrm{P}<0,05)$. Ainda, verifica-se que o período de colheita de cada híbrido, para a obtenção dos cinco estádios de maturação, variou, em função das características de crescimento de cada híbrido (Tabela 2). Este comportamento, segundo Lopes \& Maestri (1981), é explicável devido às transformações governadas tanto pelas condições internas de crescimento da planta (composição morfológica e translocação de nutrientes), como pelas externas (temperatura e umidade).

A partir das equações de regressões da Tabela 2, ficou evidenciado que, com o avanço do estádio de maturidade, a proporção da espiga em relação a planta inteira é maior, devido à compensação dos processos de formação e translocação de substâncias orgânicas para o grão (Hunter, 1978; Johnson et al., 1985; Émile \& Barrière, 1992; Demarquilly, 1994). A importância da maior participação da espiga na melhoria do valor nutritivo da forragem foi realçado por Ferreira (1990b). Neste contexto, Deinum et al. (1984) observaram valores de digestibilidade da matéria orgânica da espiga, com o grão no estádio farináceo de até $85 \%$. Portanto, a maior participação da espiga é desejável como característica que pode elevar o teor de MS da planta e influir na melhoria da qualidade da forragem e da silagem. No entanto, Johnson et al. (1985) ressaltaram que a melhoria da qualidade da silagem também está relacionada à maior qualidade de todos os outros componentes estruturais da planta de milho.

Verificou-se correlação significativa entre a percentagem de espiga na planta inteira e os componentes estruturais da planta e seus pesos, por meio dos valores de $\mathrm{R}^{2}$, sendo esta correlação positiva para os teores de matéria seca $\left(\mathrm{R}^{2}=78,74 \%\right)$, para

Tabela 1 - Percentagens médias de espiga, grão, sabugo + palha e lâmina foliar, em relação à produção de matéria seca da planta inteira dos diferentes híbridos de milho (t/ha)

Table 1 - Percentage mean the ear, grain, cob + straw and leaf lamina in relation a production dry matter the whole-plant at different corn hybrid

\begin{tabular}{|c|c|c|c|c|}
\hline $\begin{array}{l}\text { Híbrido } \\
\text { Hybrid }\end{array}$ & $\begin{array}{l}\text { \% Espiga } \\
\% \text { ear\% }\end{array}$ & $\begin{array}{l}\text { \%Grão } \\
\text { grain\% }\end{array}$ & $\begin{array}{c}\text { \% Sabugo+Palha } \\
\text { cob+straw }\end{array}$ & $\begin{array}{c}\text { \% Lâmina foliar } \\
\text { \% leaf lamina }\end{array}$ \\
\hline P32R21 & $70,25 \mathrm{a}$ & $54,20 \mathrm{a}$ & $16,05 \mathrm{a}$ & $10,54 \mathrm{a}$ \\
\hline P30R07 & $68,00 \mathrm{~b}$ & $51,28 \mathrm{~b}$ & $16,72 \mathrm{~b}$ & $13,11 b$ \\
\hline P3041 & $65,08 \mathrm{c}$ & $47,75 \mathrm{c}$ & $17,35 \mathrm{bc}$ & $13,10 \mathrm{~b}$ \\
\hline P30F33 & $68,44 \mathrm{~b}$ & $47,46 \mathrm{c}$ & $19,59 \mathrm{c}$ & $12,43 \mathrm{~b}$ \\
\hline P30F80 & $63,62 \mathrm{c}$ & $44,03 \mathrm{~d}$ & $20,97 \mathrm{c}$ & $14,24 \mathrm{c}$ \\
\hline CV\% & 2,53 & 6,86 & 20,45 & 6,81 \\
\hline
\end{tabular}

Médias, na coluna, seguidas de letras diferentes diferem entre si $(P<0,05)$ pelo teste Tukey.

Means, within a column, followed by different letters are different $(P<.05)$ by Tukey test. 
o peso do grão em $\mathrm{kg} / \mathrm{ha}\left(\mathrm{R}^{2}=73,23 \%\right)$ e para a percentagem de grão $\left(R^{2}=68,82 \%\right)$. Por outro lado, a percentagem de espiga na planta inteira correlacionou-se, negativamente, com a percentagem de colmo + bainha $\left(R^{2}=-93,54 \%\right)$, com a percentagem de lâmina foliar $\left(R^{2}=-90,09 \%\right)$, com o peso da lâmina foliar em $\mathrm{t} / \mathrm{ha}\left(\mathrm{R}^{2}=-65,49 \%\right)$, e com o peso do colmo + bainha em $\mathrm{t} / \mathrm{ha}\left(\mathrm{R}^{2}=-63,93 \%\right)$.

A partir das equações de regressão (Tabela 2) obtidas para a percentagens de grãos em função de dias pós plantio (DPP), e considerando o período total de colheita, de cada híbrido, podemos observar que para o híbrido superprecoce P32R21, a maior proporção de grãos foi de $60,33 \%$, alcançada aos 151 DPP e teor de MS na planta de 39,27\%. Enquanto que, para o híbrido precoce P30R07, foi observado a maior proporção de grãos, entre os híbridos avaliados, de 73,07\% aos 156 DPP, porém com teor de MS na planta de $48,27 \%$. Para este mesmo teor de MS $(48,28 \%)$, porém atingido aos $164 \mathrm{DPP}$, o semiprecoce P30F80 apresentou proporção máxima de grãos de $45,30 \%$. Os híbridos precoce P3041 e o precoce P30F33 produziram no máximo 54,49 e $52,90 \%$ de grãos, respectivamente, com teores de MS em torno de 41,00\%, aos 157 DPP. Estes resultados concordam com as observações de Nussio (1991) de que, nos híbridos precoces, nota-se tendência mais acentuada de translocação de sólidos solúveis dos órgãos da planta para a formação do grão, em relação aos híbridos normais ou mais tardios.

A proporção de grãos e os teores de matéria seca da planta inteira, nos diferentes estádios de maturação,

Tabela 2 - Equações de regressão para os teores de matéria seca (\%MS), percentagens de espiga (\%E), grãos (\%G), sabugo + palha (\%SP) e lâmina foliar (\%LF), em relação à produção de MS da planta inteira, dos híbridos de milho, nos diferentes estádios de maturação, em função dos dias pós-plantio (DPP)

Table 2 - Regression equation at the dry matter(\%DM), percentage ear (\%E), grain (\%G), cob + straw (\%CS) and leaf lamina (\%LL) the corn hybrid in relation the dry matter the whole-plant at different stages of maturity as a function of age (days after seeding -DAS)

\begin{tabular}{|c|c|}
\hline $\begin{array}{l}\text { Híbrido } \\
\text { Hybrid }\end{array}$ & $\begin{array}{c}\text { Equação de regressão } \\
\text { Regression equation }\end{array}$ \\
\hline P32R21 1 & $\% \mathrm{MS}=7434-1789-126,1 * \mathrm{DPP}+0,9373 * \mathrm{DPP}^{2}-0,002305 * \mathrm{DPP}^{3}$ \\
\hline P30R072 & $\% \mathrm{MS}=7434-158,5 * \mathrm{DPP}+1,125 * \mathrm{DPP}^{2}-0,002644 * \mathrm{DPP}^{3}$ \\
\hline P3041 3 & $\% \mathrm{MS}=7434-684,4-143,1 \mathrm{DPP}+1,009 * \mathrm{DPP}^{2}-0,002355 * \mathrm{DPP}^{3}$ \\
\hline $\mathrm{P} 30 \mathrm{~F} 33^{4}$ & $\% \mathrm{MS}=7434-6502-19,91 \mathrm{DPP}+0,1432 * \mathrm{DPP}^{2}-0,0003342 * \mathrm{DPP}^{3}$ \\
\hline $\mathrm{P} 30 \mathrm{~F} 80^{5}$ & $\% \mathrm{MS}=7434-12711+106,7 * \mathrm{DPP}-0,7169 * \mathrm{DPP}^{2}+0,001609 * \mathrm{DPP}^{3}$ \\
\hline P32R21 & $\% \mathrm{E}=40,34+0,219 * \mathrm{DPP}$ \\
\hline P30R07 & $\% \mathrm{E}=19,81+0,34 * \mathrm{DPP}$ \\
\hline P3041 & $\% \mathrm{E}=16,61+0,34 * \mathrm{DPP}$ \\
\hline P30F33 & $\% \mathrm{E}=19,13+0,34 * \mathrm{DPP}$ \\
\hline P30F80 & $\% \mathrm{E}=21,86+0,278 * \mathrm{DPP}$ \\
\hline P32R21 & $\% \mathrm{G}=-4,29+0,428 * \mathrm{DPP}$ \\
\hline P30R07 & $\% \mathrm{G}=-395,86+5,97 * \mathrm{DPP}-0,019 * \mathrm{DPP}^{2}$ \\
\hline P3041 & $\% \mathrm{G}=-18,83+0,47 * \mathrm{DPP}$ \\
\hline P30F33 & $\% \mathrm{G}=-7,38+0,384 * \mathrm{DPP}$ \\
\hline P30F80 & $\% \mathrm{G}=-13,22+0,38 * \mathrm{DPP}$ \\
\hline P32R21 & $\% \mathrm{SP}=195,14+3,28 * \mathrm{DPP}-0,0126 * \mathrm{DPP}^{2}$ \\
\hline P30R07 & $\% \mathrm{SP}=405,32-5,49 * \mathrm{DPP}+0,019 * \mathrm{DPP}^{2}$ \\
\hline P3041 & $\% \mathrm{SP}=549,37-7,428 * \mathrm{DPP}+0,0257 * \mathrm{DPP}^{2}$ \\
\hline P30F33 & $\% \mathrm{SP}=-119,20+2,008 * \mathrm{DPP}-0,00715 * \mathrm{DPP}^{2}$ \\
\hline P30F80 & $\% \mathrm{SP}=846,45-11,02 * \mathrm{DPP}+0,0365 * \mathrm{DPP}^{2}$ \\
\hline P32R21 & $\% \mathrm{LF}=93,76-1,132 * \mathrm{DPP}+0,0038 * \mathrm{DPP}^{2}$ \\
\hline P30R07 & $\% \mathrm{LF}=37,22-0,1832 * \mathrm{DPP}$ \\
\hline P3041 & $\% \mathrm{LF}=37,55-0,1728 * \mathrm{DPP}$ \\
\hline P30F33 & $\% \mathrm{LF}=26,97-0,074 * \mathrm{DPP}-0,00018 * \mathrm{DPP}^{2}$ \\
\hline P30F80 & $\% \mathrm{LF}=36,90-0,1512 * \mathrm{DPP}$ \\
\hline
\end{tabular}

DPP: colheita pós plantio (dias) (DAS: days after seeding, days).

1 Período de colheita de 125 a 151 DPP (Harvest period from 125 to 151 DAS).

2 Período de colheita de 128 a 156 DPP (Harvest period from 128 to 156 DAS).

3 Período de colheita de 127 a 156 DPP (Harvest period from 127 to 156 DAS).

4 Período de colheita de 129 a 157 DPP (Harvest period from 129 to 157 DAS).

5 Período de colheita de 135 a 164 DPP (Harvest period from 135 to 164 DAS). 
apresentaram correlação positiva e significativa $\left(\mathrm{R}^{2}=54,34 \%\right)$. A percentagem de grãos foi ainda correlacionada com a percentagem de espiga $\left(\mathrm{R}^{2}=64,03 \%\right)$ e inversamente com a percentagem de palha + sabugo $\left(R^{2}=-76,24 \%\right)$. Segundo Ferreira (1990b), é desejável maior proporção de grãos e espigas no material a ser ensilado, pois contribuem para melhorar a qualidade da forragem e, conseqüentemente, da silagem. Demarquilly (1994) encontrou correlação significativa entre digestibilidade e o teor de grão, porém, essa correlação não explicou mais que $50 \%$ da variação observada na digestibilidade da MS e os outros $50 \%$ foram creditados à digestibilidade do colmo.

No presente trabalho, o teor de grão apresentou baixa correlação com a digestibilidade in vitro da matéria orgânica da planta inteira $\left(R^{2}=26,49 \%\right)$. Todavia, ao observar os híbridos que apresentaram a maior (P32R21) e a menor proporção de grãos (P30F80) e ao considerar aproximadamente um valor de $80 \%$ para a digestibilidade da fração grão (Nussio et al., 2001), pode-se inferir grande participação dessa fração para a digestibilidade potencial da planta inteira. O híbrido superprecoce P32R21 cuja participação de grãos foi em média de $54,20 \%$, contribuirá em torno de 43 unidades percentuais de digestibilidade e o híbrido semiprecoce P30F80 com $44,03 \%$ de grãos contribuirá com 35 unidades percentuais de digestibilidade.

A literatura mostra divergência entre os autores, quanto a utilizar a produção de grãos, como bom indicativo, para os programas de seleção de cultivares de milho para silagem (Johnson et al., 1985; Émile \& Barrière, 1992; Demarquilly, 1994; Mayombo et al., 1997). Além da percentagem de grãos na massa ensilada (\% na MS), também a digestibilidade verdadeira da MS da porção hastes + folhas devem ser fatores a serem incluídos nos modelos de previsão de qualidade da silagem (Nussio, 2001). Ainda, esses autores justificam o uso da proporção de grãos como um dos critérios importante na escolha de materiais da silagem, pois está correlacionado com o potencial de produção de grãos e de MS total da planta.

Foi observado comportamento quadrático $(\mathrm{P}<0,05)$ para os teores de sabugo + palha em função de DPP (Tabela 2). De modo geral, o ponto de máximo de sabugo + palha em relação à planta inteira verificouse com menor teor de MS, diminuindo à medida que avança a maturidade, isto é, com o aumento no teor de MS da planta. Observou-se que para o híbrido superprecoce P32R21, aos 130 DPP (MS=26,10\%), apresentou um valor máximo de $18,32 \%$ de sabugo + palha, e um valor mínimo de $12,84 \%$ aos 151 DPP $(\mathrm{MS}=40,53 \%)$. Também o híbrido precoce P3041 apresentou valor máximo de $20,52 \%$ de sabugo + palha aos 127 DPP com 26,11\% MS, e a concentração mínima de sabugo + palha de $12,65 \%$ aos144 DPP com 33,83\%. O híbrido precoce P30R07 apresentou valor máximo de $11,26 \%$ de sabugo + palha obtido com 156 DPP (MS = 48,27\%), e valor mínimo de $8,74 \%$ aos 144 DPP (MS $=43,05 \%)$. Já o híbrido precoce P30F33 apresentou seu ponto de inflexão da curva inverso aos dos demais híbridos, sendo o valor máximo de $21,78 \%$ de sabugo + palha com menor teor de MS de 34,27\% aos 140 DPP e valor mínimo de 19,81\% de sabugo + palha com 42,54\% MS aos 157 DPP. O híbrido semiprecoce apresentou seu valor máximo 23,96\% de sabugo + palha aos 135 DPP (MS $=20,74 \%)$ e valor mínimo de 14,66\% aos 151 DPP (MS $=28,37 \%$ ).

A percentagem de sabugo + palha é um dos fatores que contribuem para diminuição do valor nutritivo da forragem, já que ambos são constituídos de parede celular de baixa qualidade, portanto esta característica deve ser melhorada pelos geneticistas. As médias de sabugo + palha nos diferentes estádios de maturação são iguais aos encontrados na literatura (Hunt et al., 1993; Flaresso et al., 2000).

$\mathrm{Na}$ Tabela 2, encontram-se as equações de regressão que melhor se ajustaram para a proporção de lâmina foliar dos híbridos de milho e DPP. Para os híbridos superprecoce P32R21 e o precoce P30F33 o comportamento foi quadrático, para a percentagem de lâmina foliar, com o avanço do estádio de maturidade, e para os demais este comportamento foi linear decrescente.

Para a percentagem de lâmina foliar dos híbridos de milho, considerando a faixa entre 30 a $35 \%$ de MS na planta, ideal no processo de ensilagem, o híbrido superprecoce P32R21 aos 125 (28,88\% de MS) até aos 129 DPP (34,51\% de MS), apresentou pequena variação de 10,58 a 10,03\% de lâmina foliar. A maior proporção de lâmina foliar observada para este híbrido foi de $11,66 \%$ com $25,00 \%$ de MS na planta inteira e a menor de $9,49 \%$ com $37,75 \%$ de MS. Para o híbrido precoce P30R07, a redução de lâmina foliar na planta inteira foi de 13,77 para $11,54 \%$, entre $128(33,13 \%$ de MS) a 135 DPP (34,98\% de MS). Já o híbrido precoce P3041 variou de 13,35 a 12,49\% de lâmina foliar, entre 140 (29,88\% de MS) e 145 DPP $(34,81 \%$ de MS). No entanto, o híbrido precoce P30F33 apre- 
sentou a maior proporção de lâmina foliar de 14,42\% aos 129 DPP com $29,17 \%$ de MS e reduziu para $12,95 \%$ de lâmina foliar, aos 141 DPP com $34,81 \%$ de MS na planta. A menor proporção de folhas observada para o P30F33 foi de $10,91 \%$ com $42,54 \%$ de MS aos 157 DPP. O híbrido semiprecoce P30F80 apresentou redução de 13,46 para 12,40\% de lâmina foliar, quando atingiu 155 e $162 \mathrm{DPP}$, com teor de 29,69 e $34,78 \%$ de matéria seca, respectivamente.

Verificou-se correlação negativa $\left(\mathrm{R}^{2}=-69,58 \%\right)$ entre a percentagem de lâmina foliar e os teores de matéria seca da planta inteira nos diferentes estádios de maturação.

A proporção de colmo + bainha na matéria seca da planta inteira, diferiu $(\mathrm{P}<0,01)$ entre híbridos. Observouse um efeito cúbico da percentagem de colmo + bainha dos diferentes híbridos, em função de DPP (Tabela 3). As percentagens médias variaram de 18,89 a 22,13\%, sendo o menor valor observado para o híbrido precoce P30R07 e, o maior valor, para o híbrido semiprecoce P30F80. Estes resultados são inferiores aos 24,50 e $31,93 \%$ de colmo, encontrados por Henrique et al. (1994) nos híbridos Co-29 (Colorado) e C-135 (Cargill), colhidos quando apresentavam seus grãos no estádio farináceo.

Considerando teores de MS na planta inteira de 30 a $35 \%$, e por meio das equações de regressão observa-se que, para o híbrido superprecoce P32R21, a proporção de colmo + bainha variou de 18,83\% $(29,88 \%$ MS) a $17,10 \%$ (34,51\% MS), sendo obtida entre 132 a 137 DPP. Para o híbrido precoce P30R07, foi observado que, aos $128 \mathrm{DPP}$, a proporção de colmo + bainha foi de 21,94\% (33,13\% MS) e, aos 135 DPP, foi de 21,05\% (34,39\% MS). Todavia, o híbrido precoce P3041 apresentou $24,71 \%$ de colmo + bai- nha, no teor de $29,88 \%$ de MS, aos 127 DPP e 22,26\% de colmo + bainha, no teor de $34,81 \%$ de MS, aos 140 DPP. Para o híbrido precoce P30F33, verificou-se que a variação nos teores de MS de 29,93\% a 34,81\%, que foi obtida entre 131 a 141 DPP, diminuiu de $22,41 \%$ para $18,01 \%$ de colmo + bainha. Já o híbrido semiprecoce P30F80 apresentou 22,04\% de colmo + bainha, quando atingiu o teor de MS de $29,69 \%$ aos 155 DPP e 20,72\% de colmo + bainha, com $34,78 \%$ de MS aos 162 DPP. Entre os híbridos avaliados a menor proporção de colmo+bainha foi verificado para o superprecoce P32R21.

Segundo Nussio (1991) e Demarquilly (1994), o colmo + bainha representa $45 \%$ da MS no início da formação do grão e diminui para 24\%, quando o grão amadurece. Ainda, Nussio (1991) relatou que para melhorar a qualidade de haste do milho, para produção de silagem de alta qualidade, seria necessário um incremento da ordem de $20 \%$ na digestibilidade do colmo, para compensar a baixa participação de grãos para os materiais mais tardios, ainda assim, concorrendo com o baixo teor de matéria seca.

A percentagem de colmo + bainha apresentou correlações significativas e negativas com os teores de matéria seca da planta inteira $\left(\mathrm{R}^{2}=-74,76 \%\right)$, com a percentagem de espiga na planta inteira $\left(R^{2}=-93,54 \%\right)$, com a percentagem de lâmina foliar na planta inteira $\left(\mathrm{R}^{2}=-68,94 \%\right)$, com a produção $(\mathrm{t} / \mathrm{ha}) \mathrm{de}$ grão $\left(\mathrm{R}^{2}=-57,21 \%\right)$ e com a percentagem de grão na planta inteira $\left(R^{2}=-56,88 \%\right)$. Porém, a percentagem de colmo + bainha correlacionou-se positivamente com a produção (t/ha) de lâmina foliar $\left(\mathrm{R}^{2}=60,32 \%\right)$ e com a produção (t/ha) de colmo + bainha $(\mathrm{R}=72,45 \%)$.

Tabela 3 - Percentagens médias e equações de regressão para a percentagem de colmo + bainha (\%CB), em relação à matéria seca da planta inteira dos híbridos de milho, nos diferentes estádios de maturação em função de dias pós plantio (DPP)

Table 3 - $\quad$ Percentage mean and regression equation at the percentage the stem + sheath (\%SS) in relation the dry matter the wholeplant corn hybrid, at different stages of maturity as function of age (DAS)

\begin{tabular}{lcc}
\hline $\begin{array}{l}\text { Híbrido } \\
\text { Hybrid }\end{array}$ & $\begin{array}{c}\text { Médias } \\
\text { Means }\end{array}$ & $\begin{array}{c}\text { Equação de regressão } \\
\text { Regression equation }\end{array}$ \\
\hline P32R21 & 19,20 & $\% \mathrm{CB}=-3758+83,15 \mathrm{DPP}-0,6076 * \mathrm{DPP}^{2}+0,001473 * \mathrm{DPP}^{3}$ \\
$\mathrm{P} 30 \mathrm{R} 07$ & 18,89 & $\% \mathrm{CB}=-3758+1895+40,91 * \mathrm{DPP}-0,2942 * \mathrm{DPP}^{2}+0,0007003 * \mathrm{DPP}^{3}$ \\
P3041 & 21,81 & $\% \mathrm{CB}=-3758+3039+17,08 * \mathrm{DPP}-0,1243 * \mathrm{DPP}^{2}+0,0002975 * \mathrm{DPP}^{3}$ \\
$\mathrm{P} 30 \mathrm{~F} 33$ & 19,12 & $\% \mathrm{CB}=-3758+5410-31,73 * \mathrm{DPP}+0,205^{*} \mathrm{DPP}^{2}-0,0004408 * \mathrm{DPP}^{3}$ \\
P30F80 & 22,13 & $\% \mathrm{CB}=-3758+5697-38,43 * \mathrm{DPP}+0,2571 * \mathrm{DPP}^{2}-0,0005739 * \mathrm{DPP}^{3}$ \\
\hline
\end{tabular}

DPP: colheita pós-plantio (dias) (DAS: days after seeding, days).

1 Período de colheita de 125 a 151 DPP (Harvest period from 125 to 151 DAS).

2 Período de colheita de 128 a 156 DPP (Harvest period from 128 to 156 DAS).

3 Período de colheita de 127 a 156 DPP (Harvest period from 127 to 156 DAS).

4 Período de colheita de 129 a 157 DPP (Harvest period from 129 to 157 DAS).

5 Período de colheita de 135 a 164 DPP (Harvest period from 135 to 164 DAS). 


\section{Agradecimento}

À Empresa Sementes Pioneer, pela oportunidade oferecida e pelo apoio para a realização deste trabalho.

À Fundação $\mathrm{ABC}$, pelo desenvolvimento do campo experimental.

\section{Conclusões}

Os aumentos nos teores de matéria seca observados com o avanço do estádio de maturação dos híbridos de milho correlacionaram-se positivamente com as percentagens de grãos e de espigas e negativamente com as percentagens de lâmina foliar e colmo + bainha.

Dentre os componentes estruturais, a maior participação foi da espiga, contribuindo em torno de 60 a $70 \%$ da matéria seca da planta inteira, entre os híbridos avaliados.

De modo geral, a maior concentração de grãos e espigas e a menor concentração de palha + sabugo, folhas e colmo+bainha em relação à matéria seca da planta inteira foram observadas para o híbrido de milho superprecoce P32R21 e o inverso, para o híbrido tardio, o semiprecoce P30F80, enquanto os híbridos precoces apresentaram-se intermediários.

\section{Literatura Citada}

ALMEIDA FILHO, S.L. Avaliação de cultivares de milho (Zea mays L.) para silagem Viçosa, MG: Universidade Federal de Viçosa, 1996. 52p. Dissertação (Mestrado em Zootecnia) - Universidade Federal de Viçosa, 1996.

ALMEIDA FILHO, S.F.; FONSECA, D.M.; GARCIA, R. et al. Características agronômicas de cultivares de milho (Zea mays L.) e qualidade dos componentes e da silagem. Revista Brasileira de Zootecnia, v.28, n.1, p.7-13, 19499.

DEINUM, B.; STEG, A.; HOF, G. Measurement and prediction of digestibility of forage maize in the Netherlands. Animal Feeding Science Technology, v.10, n.4, p.301-313, 1984.

DEMARQUILLY, C. Facteurs de variation de la valeur nutritive du mais ensilage. Production Animal , v.7, n.3, p.177-189, 1994.

FERREIRA, J.J. Milho como forragem: eficiência a ser conquistada pelo Brasil. Informe Agropecuário, v.14, n.164, p.44-46, 1990b.

ÉMILE, J.C.; BARRIÉRE, Y. Effets de la tengeur en grain de l'ensilage de mais sur les performances zootechniques de vaches laitières. Production Animal, v.5, n.2, p.113-120, 1992.

FLARESSO, J.A.; GROSS, C.D.; ALMEIDA, E.D. Cultivares de milho (Zea mays L. e Sorgo (Sorghum bicolor (L.) Moench.) para ensilagem no alto Vale do Itajaí, Santa Catarina.Revista Brasileira de Zootecnia v.29, n.6, p.1608-1615, 2000.

HENRIQUE, W.; PERES, R.M.; FILHO, J.L.V.C. et al. Avaliação de três híbridos de milho para produção de silagem. In: REUNIÃO ANUAL DA SOCIEDADE BRASILEIRA DE ZOOTECNIA, 31., 1994, Maringá. Anais... Maringá: Sociedade Brasileira de Zootecnia, 1994. p.343.

HUBER, J.T.; GRAF, G.C.; ENGEL, R.W. Effect of maturity on nutritive value of corn silage for lactating cows. Journal of Dairy Science, v.58, n.3, p.1121-1123, 1965.

HUNTER, R.B. Selection and evaluation procedures for whole plant corn silage. Canadian Journal Animal Science, v.58, n.7, p.661-678, 1978.

HUNT, C.W.; KEZAR, W.; HINMAN, D.D. et al. Effects of hybrid and ensiling and without a microbial inoculant on the nutritional characteristics of whole plant corn. Journal Animal Science, v.71, n.1, p.38-43, 1993.

INSTITUT NATIONAL DE LA RECHERCHE AGRONOMIQUE - INRA. Rencontres chercheurs-éleveurs. Production Laitiere Magazine, v.277, n.2, p.42-50, 1998.

JOHNSON JR, J.C.; MONSON, W.G.; PETLIGREW, W.T. Variation in nutritive value of corn hybrids for silage. Nutrition Reproduction International, v.32, n.4, p.953958, 1985.

LAVEZZO, W.; LAVEZZO, O.E.N.M.; CAMPOS NETO, O. Estádio de desenvolvimento do milho. Efeito sobre produção, composição da planta e qualidade da silagem. Revista Brasileira de Zootecnia, v.26, n.4, p.675-682, 1997a.

LOPES, N.F.; MAESTRI, M. Crescimento, morfologia, partição de assimilados e produção de matéria seca do milho (Zea mays L.) cultivado em três densidades populacionais. Revista Ceres, v.28, n.157, p.268-288, 1981.

MAYOMBO, A.P.; DUFRASNE, I.; HORNICK, J.L. et al. Influence du stade de maturité de la plante de mais récoltée pour ensilage sur la composition, la digestibilité apparente, les caractéristiques de fermentation dans le rume et les performances zootechniques chez le taurillon à I'engraissement. Animal Zootech, v.46, p.43-55, 1997.

NELDER, J.A.; WEDDERBURN, R.W.M. Generalized linear models. Journal of the Royal Statistical Society, v.A135, p.370-384, 1972.

NEVENS, W.B.; DUNGAM, G.H. Yield of corn hybrids harvested for silage. Illinois: University of Illinois Agricultural Experiment Station, 1949. 34p. (Bulletim 494)

NUSSIO, L.G. Cultura de milho para produção de silagem de alto valor alimentício. In: SIMPÓSIO SOBRE NUTRIÇÃO DE BOVINOS, 4., 1991. Piracicaba. Anais... São Paulo: Fundação de Estudos Agrários "Luiz de Queiroz", 1991. 302p.

NUSSIO, L.G.; CAMPOS, F.P.; DIAS, F.N. Importância da qualidade da porção vegetativa no valor alimentício da silagem de milho. In: SIMPÓSIO SOBRE PRODUÇÃO E UTILIZAÇÃO DE FORRAGENS CONSERVADAS, 1., 2001, Maringá. Anais... Maringá, 2001. p.127-145.

SAS INSTITUTE. SAS user's guide for windows environment 8.01. Cary: 2000. 79p.

SILVA, L.F.P.; MACHADO, P.F.; FRANCISCO JR., J.C. et al. Características agronômicas e digestibilidade "in situ"da fração volumosa de híbridos de milho para silagem.Scientia Agrícola, v.56, n.1, p.171-183, 1999.

SOUZA, S.N. Milho para silagem: considerações agronômicas. Agropecuária Catarinense, v.2, n.2, p.11-14, 1989.

Recebido em: 28/02/02 Aceito em: $30 / 10 / 02$ 